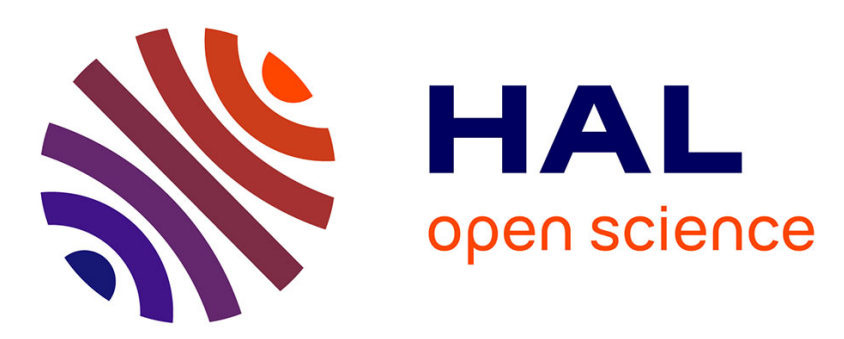

\title{
Influence of L1 prominence on L2 production: French and German speakers
}

Frank Zimmerer, Anne Bonneau, Bistra Andreeva

\section{To cite this version:}

Frank Zimmerer, Anne Bonneau, Bistra Andreeva. Influence of L1 prominence on L2 production: French and German speakers. Speech Prosody 2016, May 2016, Boston, United States. pp.370 - 374, 10.21437/SpeechProsody.2016-76 . hal-01399974

\section{HAL Id: hal-01399974 https://hal.inria.fr/hal-01399974}

Submitted on 21 Nov 2016

HAL is a multi-disciplinary open access archive for the deposit and dissemination of scientific research documents, whether they are published or not. The documents may come from teaching and research institutions in France or abroad, or from public or private research centers.
L'archive ouverte pluridisciplinaire HAL, est destinée au dépôt et à la diffusion de documents scientifiques de niveau recherche, publiés ou non, émanant des établissements d'enseignement et de recherche français ou étrangers, des laboratoires publics ou privés. 


\title{
Influence of L1 prominence on L2 production - French and German speakers
}

\author{
Frank Zimmerer ${ }^{1}$, Anne Bonneau ${ }^{2}$, Bistra Andreeva ${ }^{1}$ \\ ${ }^{1}$ Computational Linguistics and Phonetics, Saarland University, Saabrücken, Germany \\ ${ }^{2}$ Speech Group, LORIA, Inria, Villers-lès-Nancy, F-54600, France \\ Université de Lorraine, LORIA, UMR 7503, Villers-lès-Nancy, F-54600, France \\ CNRS, LORIA, UMR 7503, Villers-lès-Nancy, F-54600, France
}

zimmerer|andreeva@coli.uni-saarland.de, anne.bonneau@loria.fr

\begin{abstract}
French and German differ with respect to the representation and implementation of prominence. French can be assumed to have no prominence represented in the mental lexicon and accents are regularly assigned post-lexically on the last full vowel of an accentual group. In German, prominence is considered to be represented lexically. This difference may give rise to interferences when German speakers learn French and French speakers learn German. Results of a judgment task (conducted with 3 trained phoneticians) of native and nonnative productions of French learners of German and German learners of French, all of them beginners, show that both groups have not completely acquired the correct suprasegmental structures in the respective L2, since both groups are worse concerning the correct placement of prominence than the native speakers. Furthermore, the results suggest that the native pattern is one of the most important factors for wrong prominence placements in the foreign language, e.g., if the prominence placement of L1 and L2 coincide, speakers produce the smallest amount of errors. Finally, results indicate that visual display of accented syllables increases the likelihood of correct accent placement significantly.
\end{abstract}

Index Terms: Prominence, L1-L2 interference, French, German

\section{Introduction}

Achieving a native(-like) proficiency in a foreign language (L2) is difficult when this language is not learned as a young child. The difficulties comprise many aspects of the L2, but, the phonetics and phonology of a L2 have proven to be very difficult (e.g., among many others, [1-3]). The difficulties in acquisition are not limited to segmental differences. They also include difficulties with suprasegmental features of L2. Concerning segmental difficulties, the English /1-r/ contrast may be illustrative, where Japanese speakers have been shown to struggle to acquire it, but where training may help (e.g., [46]). One example for a suprasegmental pattern that is difficult to learn are tones in tone-languages (e.g., Mandarin Chinese) for speakers with no tones in their L1 (or a different tonal setup) (e.g., $[7,8]$ ). Another suprasegmental aspect which is not easy to learn is the correct use of prominence patterns (e.g., [9]), which are the focus of this article.

In German, the position of word stress is quite variable in monomorphemic words (e.g., [10-12]). Despite some regularities and seeming preferences for some stress patterns, language learners of German have to memorize which syllable is stressed in polysyllabic, monomorphemic words. For instance, if the orthographic string $<$ August $>$ in German is stressed on the first syllable, it refers to a male person whose name is August, whereas if the last syllable is stressed, it refers to the eighth month of the year. In the experiment reported below, trisyllabic words were produced, where the stress falls either on the first, second, or third syllable. Research indicates that for native German listeners words which are stressed on the wrong syllable are harder to recognize (e.g., [13]).

In contrast, French behaves differently. French is assumed to be a language without word stress by most researchers. Instead, accent is assumed to be regular on the last syllable of a phrase with a full vowel (e.g., [14-18]), acoustically realized often as lengthening. In trisyllabic words, a secondary accent may also be placed on the first syllable ([18]: 197). This is true as well for all the words used in the experiment reported below. Because the words were uttered in isolation (i.e., as a phrase), each word can be assumed to have an accent. This prominence pattern regularity (or the complete lack of stress) has been shown to have an influence on L2 perception, where French learners have been found persistently to be "stressdeaf" with regard to Spanish [19].

Due to the difference between German and French, we will mainly refer to prominence patterns. For our investigation, it is not crucial whether this prominence pattern is stored in the mental lexicon or assigned post-lexically, we are mainly interested in whether speakers produce the correct prominence pattern or not.

In this article, we investigate to what extent French learners of German and German learners of French are able to produce the correct prominence pattern in the respective $\mathrm{L} 2$ on cognates. We additionally analyse whether L1 prominence patterns have an effect on production and whether visually highlighted prominent syllables have an effect. A production experiment was carried out in which words were read in isolation. In a judgment task, the prominent syllable was indicated for the learner utterances. These judgments are used to evaluate the performance of the language learners. We predicted that both groups of learners show a tendency to transfer native prominence patterns onto the words in the L2. We also expected to find that German speakers are somewhat more successful in suppressing the native prominence patterns, because a) the French pattern is regular, and b) the awareness for prominence may be somewhat more pronounced for German learners of French, because it is more important in 
German where stress can be assumed to be stored in the mental lexicon. Furthermore, we predicted that prominent syllables highlighting would facilitate correct production for the learners, and lead to fewer mistakes.

\section{Perceptual judgments of learner productions}

\subsection{Materials and Methods}

For the production task which was the basis for the judgment task, 30 trisyllabic words were selected, based on [13]. They were cognates in German and French. In German, 10 of these words have main stress on the first syllable (e.g., Albatros, 'albatross'), 10 of the words are stressed on the second syllable (e.g., Embargo, 'embargo'), and another 10 words are stressed on the final syllable (e.g., Labyrinth/labyrinthe, 'labyrinth'). As explained above, for French we assume that for all these words the final syllable is the most prominent. None of the words was highly frequent. However, because they were cognates, we assumed that the speakers understood the words also in their respective L2. Additionally, none of the speakers asked for the meaning of the word, although they were told to in case they did not know a word.

10 French learners of German and 10 German learners of French were recorded for the production task. All participants were beginners (A1, A2, or B1 according to the European Framework of Reference for Languages: Learning, Teaching, Assessment (CEFR)). Half of the speakers of each language were female. The recordings were made in a quiet office in Nancy (for the French learners of German) and Saarbrücken (for the German learners of French) with the software JCorpusRecorder [20] and a head mounted microphone (AKG C520), digitized with an Audiobox (M-Audio Fast Track). During the recording, the gain was automatically controlled to avoid clippings. The speakers had to produce 3 lists. The first list contained each of the 30 words twice in the non-native language, and speakers were asked to produce the non-native words which were presented to them in a random order (French native speakers reading German (FG), and German native speakers reading French (GF)). The second list was similar, except that the prominent syllable of the non-native word was highlighted (i.e., the prominent syllable was written in blue, bold and capitalized). The third list consisted of the 60 items in the respective native language (French speakers reading French (FF) and German speakers reading German (GG)). Speakers had to click on a button to start and finish the recording. They could listen to their recordings and decide for themselves whether they wanted to rerecord a word or proceed to the next item by clicking a button on the screen. This procedure was designed to prevent participants from reading the items with a list intonation. Half of the productions of all speakers were the basis for a perceptual judgment experiment so that every word was uttered once by each speaker in each condition (i.e., list), adding up to 1800 items ( 3 conditions * 30 words $* 20$ speakers)

3 trained phoneticians from Saarbrücken and Nancy (the three authors) judged the items. One of them is a French native speaker with knowledge of German, then there is a Bulgarian native speaker who is highly proficient in German, and one is a German native speaker with knowledge of French. The phoneticians listened to each utterance and decided whether the main prominence was on the first, the second, or the third syllable of the word. Productions of F and G speakers were mixed. The experts could also indicate that they were not sure. The listeners could replay each item as often as they liked. Also, they were under no time restraint. Pauses could be made at any point in time. This task was executed in Praat [21].

\subsection{Analysis}

The responses given by the three judges were statistically analyzed with JMP [22]. Overall, 5400 responses were recorded (1800 items * 3 judges). An analysis was carried out to see if the raters' judgments were in agreement. Of the 1800 items, the rating was identical for 1033 (57.4\%) items. 155 $(8.6 \%)$ items were judged with three different responses by the raters, in 612 cases $(34 \%)$, two of the raters responded identically. The 1033 responses of full agreement contained 3 instances where all the raters were using the 'not sure' response. For the remaining 1030 items, the judges agreed on the prominent syllable. If all responses are considered, Fleiss' Kappa indicated a moderate reliability $(\kappa=0.484)$.

However, it is not clear to what extent the 'not sure' option influenced the result, because using this option does not necessarily indicate disagreement. For instance, if one rater was not quite sure whether the prominent syllable was the first or the third, and another rater indicated syllable 3 as prominent, they do not completely disagree. Therefore, items that were judged 'not sure' were replayed to the 3 judges. We wanted to know whether they could not decide between two syllables the first and second, or second and third, or first and third syllable. Again, 'not sure' was a response option. This time, each judge listened only to the items he or she rated as 'not sure' in the first run. Otherwise the procedure was identical. Of the 603 items which were judged 'not sure' in the first task, 148 were judged 'not sure' in the second. Most of the responses (395) indicated insecurity between the first and third syllable, 8 cases of insecurity occurred between first and second syllable prominence, and 52 items were based on insecurity between second and third syllable. The result of the second rating task indicates that the 'not sure' option does not necessarily show disagreement between the raters. There were 350 'not sure' items of the first task, which were rated as 'either first or third' in the second experiment (395 responses - note that sometimes more than one rater indicated 'not sure' for the same item). These 350 items (1050 responses) were rated as having main prominence on the third syllable 454 times. 128 responses indicated first syllable prominence, and 37 times, the second syllable was judged to be the most prominent. Thus, the 'not sure' responses are not necessarily a contradiction between the judgments, but because it is not obvious how exactly to deal with the 'not sure' responses, all items where at least one of the raters used this option were excluded. This left 1289 items being judged by the 3 raters (overall, 3867 responses), which were analyzed for inter-rater agreement. Of the 1289 items, the judges agreed on 1030 $(79.9 \%)$. There were 7 cases $(0.5 \%)$ in which the 3 raters had 3 different judgments. In $19.6 \%$ of the cases (252 items), at least two of the raters were in agreement. For this subset, Fleiss' Kappa indicated a higher inter-rater agreement $(\kappa=0.743)$. From this subset, we selected the cases where all raters agreed, leaving 1030 items (3090 responses) for further analysis. This subset can be seen as representing rather confident ratings.

\section{Results}

First, we analyze how often the judges indicated that the learners were successful in producing prominence on the 
correct syllable, also in comparison to the productions of the respective native speakers. Each language will be examined in turn

Concerning the productions of the German words (conditions GG and FG), 601 items were judged by the raters. 233 of them were produced by German native speakers (GG). French speakers produced 136 items without visual indication of prominence and 232 with indication of prominence (summing up to 368 items). Overall, 146 (43 in the GG condition, 103 in the FG condition) words had prominence on the first syllable, 206 (96 in the GG condition, 110 in the FG condition) on the second and 249 (94 in the GG condition, 155 in the FG condition) on the third syllable. The productions by German speakers (GG) were rated as having the prominent syllable canonically in $98 \%$ of the cases, whereas the French productions (FG) were rated as such $82 \%$ of the time. To further investigate this pattern, a linear mixed model (LMM) was calculated with canonical productions labeled as ' 1 ' and ' 0 ' otherwise. The LMM had CORRECTNESS as dependent factor, SUBJECT and ITEM as random factors, as well as NATIVE LANGUAGE, CANONICALLY PROMINENT SYLLABLE and their interaction as independent factors. Results indicated that all factors and the interaction were significant (NATIVE LANGUAGE $\mathrm{F}(1,22.43)=21.94, \quad \mathrm{p}<0.0001, \quad$ CANONICALLY PROMINENT SYLLABLE $F(2,26,86)=19.31 \mathrm{p}<0.0001$ and the interaction $\mathrm{F}(2,574,3)=19.06, \mathrm{p}<0.0001)$. A post-hoc analysis showed that the productions of the French speakers were significantly less often rated as correct if the canonically prominent syllable was not the last one compared to all the productions of the German native speakers, as well as with respect to French speakers' productions of words where the last syllable was canonically prominent

Table 1. Words in German, produced by German $(G)$ and French $(F)$ speakers. The first column indicates the canonically prominent syllable in German (the prominent syllable in $F$ in parentheses). Columns 2-4 indicate the percentage of responses by the raters. In bold are the cases which were rated as canonical.

\begin{tabular}{|c|c|c|c|}
\hline Canon promi & \multicolumn{3}{|c|}{ Response } \\
\cline { 2 - 4 } G (F) & $1^{\text {st }}$ & $2^{\text {nd }}$ & $3^{\text {rd }}$ \\
\hline G-1 (3) & $\mathbf{9 0 \% ( 3 9 )}$ & $5 \%(2)$ & $5 \%(2)$ \\
G-2(3) & $0 \%(0)$ & $\mathbf{1 0 0 \% ( 9 6 )}$ & $0 \%(0)$ \\
G-3 (3) & $0 \%(0)$ & $0 \%(0)$ & $\mathbf{1 0 0 \% ( 9 4 )}$ \\
F-1 (3) & $\mathbf{7 3 \% ( 7 5 )}$ & $3 \%(3)$ & $24 \%(25)$ \\
F-2(3) & $19 \%(21)$ & $\mathbf{6 6 \% ( 7 3 )}$ & $15 \%(16)$ \\
F-3 (3) & $1 \%(1)$ & $0 \%(0)$ & $\mathbf{9 9 \%}(\mathbf{1 5 3})$ \\
\hline
\end{tabular}

We can interpret this result as reflecting some problems for French native speakers to produce the correct prominence pattern if the prominent syllable is not the last one, which would be the prominent one in French. This becomes more evident when the words are grouped according to which syllable is canonically prominent in German (Table 1). The productions of German native speakers were rated to have produced prominence on the correct syllable in German most of the time $(90 \%, 100 \%$, and $100 \%$ respectively). The picture for French speakers is different. While the learners were very successful to produce the accented syllable when prominence fell on the third syllable (99\%), the productions proved to be less successful when prominence should have been on the first syllable $(73 \%$ correct $)$. In this case, French learners also produced prominence on the third syllable quite often (24\%). An interesting pattern emerged for the words with canonical prominence on the second syllable. Here, French learners correctly placed the prominence in $66 \%$ of the cases, but produced prominence almost equally often on the first or the last syllable ( $19 \%$ and $15 \%$ respectively).

Next, the productions of the French words are analyzed (Conditions FF and GF). 429 items were judged by the raters. 99 items were produced by French native speakers (FF). German speakers produced 330 items (142 without visual indication of prominence and 188 with indication of prominence). The productions by French native speakers (FF) were rated as having prominence on the third syllable in $100 \%$ of the cases, whereas the German productions were rated as having prominence on the canonical syllable $94 \%$ of the time. The words were also grouped according to the prominence patterns of German, to see whether German learners transferred the native prominence pattern to French words (see Table 2). If the raters judged the canonically prominent syllable as the third syllable, this was labeled as ' 1 ', and ' 0 ' otherwise. A LMM was calculated, with CORRECTNESS as dependent factor, SUBJECT and ITEM as random factors, as well as NATIVE LANGUAGE, and CANONICALLY PROMINENT SYLLABLE IN GERMAN and the interaction of the two factors as independent variables. In this model, NATIVE LANGUAGE was found to be a significant factor $(\mathrm{F}(1,31.98)=9.69, \mathrm{p}<0.01$; CANONICALLY PROMINENT SYLLABLE IN GERMAN $(\mathrm{F}(2,23.62)=5.18, \quad \mathrm{p}<0.05), \quad$ and the interaction $(\mathrm{F}(2,394.1)=9.3, \mathrm{p}<0.0001)$ were found to be significant. The analysis indicates that French native speakers were more successful in producing prominence on the canonical syllable, compared to German learners of French, and that the words with second syllable prominence produced by German speakers were worse than the other conditions.

Table 2. Words in French, produced by French $(F)$ and German $(G))$ speakers. The first column indicates the canonically prominent syllable in German (the prominent syllable in $G$ in parentheses). Columns 2-4 indicate the percentage of responses by the raters. In

bold are the cases which were rated as canonical.

\begin{tabular}{|c|c|c|c|}
\hline \multirow{2}{*}{$\begin{array}{l}\text { Canon } \\
\text { promi F (G) }\end{array}$} & \multicolumn{3}{|c|}{ Response } \\
\cline { 2 - 4 } & $1^{\text {st }}$ & $2^{\text {nd }}$ & $3^{\text {rd }}$ \\
\hline F-3 (1) & $0 \%(0)$ & $0 \%(0)$ & $\mathbf{1 0 0 \%}(\mathbf{2 9})$ \\
F-3 (2) & $0 \%(0)$ & $0 \%(0)$ & $\mathbf{1 0 0 \% ( 2 2 )}$ \\
F-3 (3) & $0 \%(0)$ & $0 \%(0)$ & $\mathbf{1 0 0 \% ( 4 8 )}$ \\
G-3 (1) & $3 \%(3)$ & $0 \%(0)$ & $\mathbf{9 7 \% ( 9 6 )}$ \\
G-3 (2) & $0 \%(0)$ & $25 \%(18)$ & $\mathbf{7 5 \% ( 5 5 )}$ \\
G-3 (3) & $0 \%(0)$ & $0 \%(0)$ & $\mathbf{1 0 0 \% ( 1 5 8 )}$ \\
\hline
\end{tabular}

French native speakers were rated as having produced prominence most often on the correct (i.e., third) syllable $(100 \%)$ in all prominence conditions. German speakers on the other hand show more variation. In case where the stress in German and the accent in French coincide, German speakers were rated as being always successful $(100 \%)$. However, when the second syllable is stressed in German, they also produced prominence on the second syllable of $\mathrm{F}$ words quite often (25\%), and $75 \%$ correct. The pattern for words which have prominence on the first syllable in German falls somewhere in between, apart from the correct prominence placement $(97 \%)$ there are also some cases of first syllable prominence (3\%).

The question whether visual indication helps to improve the production is investigated next. In this analysis, only the learner productions were investigated (FG and GF). Tables 3 and 4 show the effect of the visual highlighting of the 
prominent syllable. Both groups benefited from visual indication of prominence. French speakers' ratings improved from $63 \%$ correct to $92 \%$ correct. The improvement occurred with all prominence patterns $(49 \%$ to $85 \%$ for first syllable prominence, $19 \%$ to $89 \%$ for second syllable and $97 \%$ to $100 \%$ for third). The rating of German speakers' productions improved from $87 \%$ to $99 \%$ correct $(92 \%$ to $100 \%$ for the words with prominence on the first syllable in German, $48 \%$ to $95 \%$ for second, and $100 \%$ to $100 \%$ for the third). In a model in which CONDITION (visual, nonvisual), NATIVE LANGUAGE ( $\mathrm{F}$, G) and the interaction were entered as factors, with ITEM and SUBJECT as random effects, as well as rated CORRECT as dependent factor, all factors proved to be significant (NATIVE LANGUAGE $\quad \mathrm{F}(1,18.91)=11.6, \quad \mathrm{p}<0.01 ; \quad$ CONDITION $\mathrm{F}(1,657.5)=99.94, \quad \mathrm{p}<0.0001)$, as well as the interaction $(\mathrm{F}(1,658.1)=14.43, \mathrm{p}<0.001)$. This interaction was driven by the fact that $G$ were rated more correct in the non-visual condition, whereas there was no difference when visual help was given.

Table 3. Words in German, French $(F)$ speakers, with or without visual highlighting. The first column indicates the canonically prominent syllable in German Columns 2-4 indicate the percentage of responses by the raters. In bold are the cases which were rated as canonical.

\begin{tabular}{|c|c|c|c|}
\hline Visual-Can & \multicolumn{3}{|c|}{ Response } \\
\cline { 2 - 4 } promi G (F) & $1^{\text {st }}$ & $2^{\text {nd }}$ & $3^{\text {rd }}$ \\
\hline NoVi-1 (3) & $\mathbf{4 9 \% ( 1 7 )}$ & $3 \%(1)$ & $49 \%(17)$ \\
NoVi-2 (3) & $44 \%(16)$ & $\mathbf{1 9 \% ( 7 )}$ & $36 \%(13)$ \\
NoVi-3 (3) & $3 \%(2)$ & $0 \%(0)$ & $\mathbf{9 7 \% ( 6 3 )}$ \\
Vis-1 (3) & $\mathbf{8 5 \% ( 5 8 )}$ & $3 \%(2)$ & $12 \%(8)$ \\
Vis-2 (3) & $7 \%(5)$ & $\mathbf{8 9 \% ( 6 6 )}$ & $4 \%(43)$ \\
Vis-3 (3) & $0 \%(0)$ & $0 \%(0)$ & $\mathbf{1 0 0 \% ( 9 0 )}$ \\
\hline
\end{tabular}

\section{Discussion and Conclusions}

The research reported here was designed to answer the questions to what extent French learners of German and German learners of French were able to produce prominence correctly in their respective L2. Furthermore, we investigated whether L2 learners transferred their native prominence patterns to the L2. A third question that was investigated was concerned with the effect of visual indication of prominence in words that had to be read.

Concerning the first question, the results for the analyzed words suggest that both $F$ and $G$ learners were not always successful in producing prominence on the correct syllable. Overall, G speakers seem to be more successful. However, this result was expected, because $G$ learners have to acquire only one pattern (i.e., the last syllable is accented in French), whereas $\mathrm{F}$ learners have to learn different patterns, and have been shown to have problems with prominence (or stress) in perception (e.g. [19]). The items that were not analyzed also point towards some problems for the learners.

As for the second research question, the productions of $F$ and $\mathrm{G}$ learners suggest that there is such an influence of the L1 on the prominence placement in L2. This is especially apparent when the cognates had identical prominence placement in L1 and L2 (i.e., the last syllable): they reached the highest correctness scores with and without visual highlighting of the prominent syllable. However, there were also differences for the two speaker groups. If $G$ words had canonical prominence on the first syllable, $\mathrm{F}$ learners produced also quite numerous words with last syllable prominence, as predicted. The words with prominence on the second syllable were somewhat different. In this case, they produced some words which had prominence on the last syllable, as predicted. However, they also produced words with first syllable prominence. Two explanations may account for these findings. Firstly, prominence on the second syllable of trisyllabic words does not occur in French, whereas first syllables may be accented too, with the last syllable being sometimes reduced (e.g., $[18,23])$. Secondly, and more speculative, there may be an explanation taking into account general misperceptions about German stress, which is often assumed to be on the first syllable, due to the fact that many bisyllabic words are stressed on the first syllable, which is actually due to the reduced vowel of the second syllable (e.g. [12, 13]). F speakers could have learned this prominence pattern. $G$ speakers speaking $F$ show a clear effect of L1 stress patterns for the cognates with second syllable stress in $\mathrm{G}$, where many $\mathrm{G}$ speakers produced prominence on the second syllable rather than on the third.

Table 4. Words in French, German speakers, with or without visual highlighting. The first column indicates the canonically prominent syllable in French (prominent syllable in $G$ in parentheses). Columns 2-4 indicate the percentage of responses by the raters. In bold are the cases which were rated as canonical.

\begin{tabular}{|c|c|c|c|}
\hline Visual-Can & \multicolumn{3}{|c|}{ Response } \\
\cline { 2 - 4 } promi F (G) & $1^{\text {st }}$ & $2^{\text {nd }}$ & $3^{\text {rd }}$ \\
\hline NoVi-3 (1) & $8 \%(3)$ & $0 \%(0)$ & $\mathbf{9 2 \% ( 3 5 )}$ \\
NoV-3 (2) & $0 \%(0)$ & $52 \%(16)$ & $\mathbf{4 8 \% ( 1 5 )}$ \\
NoV-3 (3) & $0 \%(0)$ & $0 \%(0)$ & $\mathbf{1 0 0 \% ( 7 3 )}$ \\
Vis-3 (1) & $0 \%(0)$ & $0 \%(0)$ & $\mathbf{1 0 0 \% ( 6 1 )}$ \\
Vis-3 (2) & $0 \%(0)$ & $5 \%(2)$ & $\mathbf{9 5 \% ( 4 0 )}$ \\
Vis-3 (3) & $0 \%(0)$ & $0 \%(0)$ & $\mathbf{1 0 0 \% ( 8 5 )}$ \\
\hline
\end{tabular}

With regard to the third research question, results of the comparison of learner productions suggest that visual indication may indeed increase the correct prominence placement. Both groups improved significantly when the prominent syllable was visually highlighted.

This may not be the complete picture, though. Here, we were only interested whether or not learners produced prominence in cognate words on the correct syllable. We did not investigate whether or not the intonational realizations of the prominence patterns were correct. Anecdotally, all the raters reported, for instance, that despite correct prominence placement on the last syllable, many $G$ productions did not sound French-like at all. Also, connected with the 'not sure' responses, many French speakers produced a secondary prominence on the first syllable, which, in many cases, was as prominent as the last one, which was lengthened but not necessarily more prominent (cf. [24]). This led to the effect that even though $\mathrm{F}$ native productions sounded correct, the raters did not indicate that the correct syllable was prominent, and opted for the 'not sure' option. Another factor may also have been the L1 of the raters. Because there was only one speaker for each language background, this factor could be interesting to investigate in a future study.

\section{Acknowledgements}

This research was supported by DFG and ANR with a grant for the IFCASL project (www.ifcasl.org). 


\section{References}

[1] C. T. Best and M. D. Tyler, "Nonnative and secondlanguage speech perception," in Language Experience in Second Language Speech Learning: In honor of James Emil Flege, M. J. Munro and O.-S. Bohn, Eds., ed Amsterdam: John Benjamins, 2007, pp. 13-34.

[2] J. E. Flege, "Second language speech learning: Theory, findings and problems," in Speech Perception and Linguistic Experience: Theoretical and Methodological Issues in Cross-Language Speech Research, W. Strange, Ed., ed Timonium: York Press, 1995, pp. 233-272.

[3] J. Kingston, "Learning foreign vowels," Language and Speech, vol. 46, pp. 295-349, 2003.

[4] A. R. Bradlow, D. B. Pisoni, R. Akahane-Yamada, and Y. i. Tohkura, "Training Japanese listeners to identify English /r/ and /1/: IV. Some effects of perceptual learning on speech production," Journal of the Acoustical Society of America, vol. 101, pp. 2299-2310, 1997.

[5] J. S. Logan, S. E. Lively, and D. B. Pisoni, "Training Japanese listeners to identify English /r/ and /1/: A first report," Journal of the Acoustical Society of America, vol. 89, pp. 874-886, 1991

[6] K. Miyawaki, W. Strange, R. Verbrugge, A. M. Liberman, J. J. Jenkins, and O. Fujimura, "An effect of linguistic experience: Discrimination of [r] and [1] by native speakers of Japanese and English," Perception \& Psychophysics, vol. 18, pp. 331-340, 1975.

[7] Y. Wang, M. M. Spence, A. Jongman, and J. A. Sereno, "Training American listeners to perceive Mandarin tones," Journal of the Acoustical Society of America, vol. 106, pp. 3649-3658, 1999.

[8] Y. Wang, A. Jongman, and J. A. Sereno, "Acoustic and perceptual evaluation of Mandarin tone productions before and after perceptual training," Journal of the Acoustical Society of America, vol. 113, pp. 1033-1044, 2003.

[9] P. Trofimovich and W. Baker, "Learning second language suprasegmentals: Effect of L2 experience on prosody and fluency characteristics of L2 speech," Studies in Second Language Acquisition, vol. 28, pp. 130, 2006.

[10] R. Wiese, The phonology of German. Oxford et al.: Oxford University Press, 1996.

[11] K. J. Kohler, Einführung in die Phonetik des Deutschen, 2nd Edition ed. Berlin: Erich Schmidt Verlag, 1995.

[12] C. Féry, "German word stress in optimality theory," Journal of Comparative Germanic Linguistics, vol. 2, 1998.

[13] U. Domahs, R. Wiese, I. Bornkessel-Schlesewsky, and M. Schlesewsky, "The processing of German word stress: evidence for the prosodic hierarchy," Phonology, vol. 25, pp. 1-36, 2008.

[14] S.-A. Jun and C. Fougeron, "A phonological model of French intonation," in Intonation: Analysis, modeling and technology, A. Botinis, Ed., ed Dordrecht: Kluwer, 2000, pp. 209-242.

[15] E. Pustka, Einführung in die Phonetik und Phonologie des Französischen vol. 24. Berlin: Erich Schmidt Verlag, 2011.

[16] C. Féry, "Final compression in French as a phrasal phenomenon," in Perspectives on linguistic structure and context: Studies in honour of Knud Lambrecht, S. Katz
Bourns and L. L. Myers, Eds., ed Amsterdam: John Benjamins, 2014, pp. 133-156.

[17] C. Féry, "Focus and phrasing in French," in Audiatur Vox Sapientiae. A Festschrift for Arnim von Stechow, C. Féry and W. Sternefeld, Eds., ed Berlin: Akademie-Verlag 2001, pp. 153-181.

[18] A. Di Cristo, "Intonation in French," in Intonation systems: A surveyof twenty languages $\mathrm{D}$. Hirst and A. Di Cristo, Eds., ed Cambridge, England: Cambridge University Press, 1998, pp. 195-218.

[19] E. Dupoux, N. Sebastián-Gallés, E. Navarrete, and S. Peperkamp, "Persistent stress 'deafness': The case of French learners of Spanish," Cognition, vol. 106, pp. 682706,2008

[20] V. Colotte, "JCorpusRecorder," ed. Nancy: LORIA, 2015.

[21] P. Boersma and D. Weenink, PRAAT: Doing phonetics by computer, Version 5.4 ed., 2014.

[22] SAS, "JMP," 11 ed. Cary (NC): SAS Institute, 2014.

[23] J. Vaissière, "Cross-linguistic prosodic transcription: French vs. English," in Problems and methods of experimental phonetics. In honour of the 70th anniversary of Pr. L.V. Bondarko,, N. B. Volskaya, N. D. Svetozarova, and P. A. Skrelin, Eds., ed St. Petersburg: St Petersburg State University Press, 2002, pp. 147-164.

[24] J. Vaissière, "Perception of intonation," in The handbook of speech perception, D. B. Pisoni and R. E. Remez, Eds., ed Malden (MA): Blackwell Publishing, 2005, pp. 236263. 